\title{
Case Report \\ Rare Cause of Recurrent Hypoglycemia: Insulin Autoimmune Syndrome
}

\author{
Rungsima Tinmanee, Rungpailin Buranagan, Sirirat Ploybutr, \\ Raweewan Lertwattanarak, and Apiradee Sriwijitkamol
}

Division of Endocrinology and Metabolism, Department of Medicine, Faculty of Medicine Siriraj Hospital, Mahidol University, Bangkok, Thailand

Correspondence should be addressed to Apiradee Sriwijitkamol; apiradeesi99@hotmail.com

Received 19 July 2017; Accepted 18 September 2017; Published 26 November 2017

Academic Editor: Lucy Mastrandrea

Copyright ( 2017 Rungsima Tinmanee et al. This is an open access article distributed under the Creative Commons Attribution License, which permits unrestricted use, distribution, and reproduction in any medium, provided the original work is properly cited.

\begin{abstract}
We report a case of insulin autoimmune syndrome associated with several autoantibodies, presenting with recurrent hypoglycemia, predominantly in the postprandial period, which improved by dietary management and spontaneously resolved within two months. Differentiation from other causes of hyperinsulinemic hypoglycemia, such as insulinoma, is important to avoid unnecessary invasive procedures or surgical interventions. The 75-gram oral glucose tolerance test (OGTT) and mixed meal test showed a typical pattern, which may be useful indirect evidence of insulin autoimmune syndrome.
\end{abstract}

\section{Introduction}

Insulin autoimmune syndrome (IAS) or Hirata disease, a rare cause of hyperinsulinemic hypoglycemia first described by Hirata et al. in 1970 [1], is characterized by concurrent hypoglycemia with a very high insulin level and the presence of insulin autoantibodies in insulin-naïve patients [2]. Several autoimmune diseases, predominantly Graves' disease, are associated with insulin autoimmune syndrome [3-5].

\section{Case Presentation}

A 74-year-old previously healthy woman was referred to our hospital due to palpitation and sweating for one month. She did not take any medication. Her first episode of palpitation, sweating, and sleepiness was two years ago. The symptoms, which mostly occurred four hours after lunch, were improved by syrup intake. No symptom was reported in the morning. She was sent to a local hospital, and the capillary plasma glucose (CPG) during symptoms was $49 \mathrm{mg} / \mathrm{dl}$. Unfortunately, neither plasma glucose nor other critical labs were investigated to confirm or diagnose hypoglycemia at that time. Four to six grams per hour of intravenous dextrose solution could maintain her CPG at the normal level. Whole abdominal computed tomography was performed and no abnormality was detected. After the episode for 1 month, her symptoms spontaneously resolved and no more $\mathrm{CPG}$ or fasting plasma glucose was recorded. Being afraid of hypoglycemia, consumption of simple carbohydrate such as fruit juices or syrup was added in the late morning and the afternoon, which resulted in a slow gain, from 50 to $60 \mathrm{~kg}$ within 2 years, of body weight. The symptoms have been absent for the past two years. One month ago, the several episodes of palpitation and sweating recurred almost every day without any change in her diet pattern. At this time, the symptoms developed at 3 hours after lunch and alleviated after the afternoon snack ingestion. She denied using hypoglycemic agents, insulin, or any drugs or supplements. No hypothyroid or thyrotoxicosis symptoms were recognized. No fever or rash or alopecia or arthritis was experienced. No anemic symptom or polyuria or bone pain was developed. No family history of diabetes or neuroendocrine tumor was noticed. Physical examination revealed a body weight of $60 \mathrm{~kg}$, a height of $155 \mathrm{~cm}$, a body mass index of $28.5 \mathrm{~kg} / \mathrm{m}^{2}$, a temperature of $36^{\circ} \mathrm{C}$, blood pressure of $140 / 80 \mathrm{mmHg}$, a pulse of $60 \mathrm{bpm}$, and a respiratory rate of $16 / \mathrm{min}$. There was no acanthosis nigricans, lipodystrophy, rash, or needle mark 
on examination. The thyroid gland was not enlarged. No signs of thyrotoxicosis or systemic lupus erythematosus were revealed. Other findings were within the normal.

Laboratory investigations were performed as follows. Complete blood count showed normocytic anemia with hemoglobin of $9.8 \mathrm{~g} / \mathrm{dL}$ and normal white blood cell count and platelet count. Electrolyte, kidney, and liver functions were within the normal limit. Capillary plasma glucose was $43 \mathrm{mg} / \mathrm{dl}$, together with venous plasma glucose of $44 \mathrm{mg} / \mathrm{dl}$, during the episode of palpitation and sweating symptoms. Serum insulin level at that time was higher than $1,000 \mu \mathrm{U} / \mathrm{mL}$, and the level was increased to $2,628 \mu \mathrm{U} / \mathrm{mL}$ after $1: 20$ dilution. During the symptoms, she also had a high level of serum C-peptide (at a level of $8.3 \mathrm{ng} / \mathrm{mL}$ ) and serum cortisol (at a level of $26.7 \mu \mathrm{g} / \mathrm{dL}$ ) and an undetected serum $\beta$-hydroxybutyrate level (at a level of $0 \mathrm{mmol} / \mathrm{L}$ ). Therefore, endogenous hyperinsulinemic hypoglycemia was confirmed. Oral glucose tolerance test (OGTT) with 75 grams of glucose was performed. Baseline plasma glucose was $79 \mathrm{mg} / \mathrm{dL}$ and serum insulin level was $950.3 \mu \mathrm{U} / \mathrm{mL}$. Her plasma glucose increased to $221 \mathrm{mg} / \mathrm{dL}$ at two hours after OGTT. However, 5 hours after OGTT, she developed hypoglycemic symptoms with the plasma glucose dropped to $36 \mathrm{mg} / \mathrm{dL}$, together with a very high serum insulin level of $2,912 \mu \mathrm{U} / \mathrm{mL}$. Mixed meal test was also performed with the baseline plasma glucose of $84 \mathrm{mg} / \mathrm{dL}$ and insulin level of $1,219.6 \mu \mathrm{U} / \mathrm{mL}$. Symptomatic hypoglycemia was developed at 4 hours after the meal with concurrent plasma glucose of $53 \mathrm{mg} / \mathrm{dL}$ and insulin level of $2,110 \mu \mathrm{U} / \mathrm{mL}$. Because of postprandial hypoglycemia together with the extremely high level of serum insulin, the autoimmune insulin syndrome was suspected and then was confirmed by the very high level of serum insulin autoantibody, with the level of $10.7 \mathrm{nmol} / \mathrm{L}$ (normal range: $0-0.02 \mathrm{nmol} / \mathrm{L})$. Further investigations for other associated autoimmune diseases showed a high level of serum antithyroglobulin antibody and serum anti-thyroperoxidase antibody with the level of $88.84 \mathrm{U} / \mathrm{mL}$ (normal range $<35 \mathrm{U} / \mathrm{mL}$ ) and $169.26 \mathrm{U} / \mathrm{mL}$ (normal range $<65 \mathrm{U} / \mathrm{mL}$ ), respectively. She also had a positive titer of fine-speckled pattern antinuclear antibody (ANA) with the titer of $1: 320$ (normal titer $<1: 100$ ). There were no clinical clues of monoclonal gammopathy or the usage of sulfhydryl group-containing drugs in our patient.

The patient was treated by cessation of snack meals and avoidance of simple carbohydrate diet. Two days after dietary adjustment, her CPG was maintained between 65 and $130 \mathrm{mg} / \mathrm{dl}$ without requirement of intravenous dextrose solution. She was discharged without any additional therapies. The overall hypoglycemic duration of this episode was two months before the spontaneous remission. The followup laboratory investigations are shown in Table 1 . Up to 15 months after the 2 nd episode of hypoglycemia, she was fine without any symptoms of hypoglycemia.

\section{Discussion}

Insulin autoimmune syndrome (IAS or Hirata disease) is a rare cause of hyperinsulinemic hypoglycemia. To date, approximately 400 cases have been reported and more than $90 \%$ of them were Japanese patients [6]. The causes of IAS are heterogeneous, typically associated with certain HLA class II allele, the usage of sulfhydryl group-containing drugs in which methimazole is responsible for almost half of them, autoimmune diseases, monoclonal gammopathy, or hepatitis C viral infection [7]. Graves' disease was the most common autoimmune disease found in IAS [7], while other associated autoimmune diseases, including Hashimoto's thyroiditis, systemic lupus erythematosus, rheumatoid arthritis, antineutrophil cytoplasmic antibodies-associated glomerulonephritis, polymyositis, systemic sclerosis, and ankylosing spondylitis, were found infrequently [3-5]. The mechanism of endogenous autoantibody induced hypoglycemia is that, after food intake, the endogenous antibodies bind to the secreted insulin and proinsulin(s) causing the insulin to be ineffective and causing postprandial hyperglycemia, consequently increasing insulin release further. The dissociation of insulin from insulin autoantibodies resulted in extremely high levels of unbound insulin and caused hypoglycemia [8, 9]. From a previous case report, about $42 \%$ had postprandial hypoglycemia, $31 \%$ had fasting hypoglycemia, and $24 \%$ had both postprandial and fasting hypoglycemia. The majority of patients are above 40 years of age, and women and men are affected equally [10].

Because of the typical postprandial hypoglycemia and very high insulin level without signs of insulin resistance, insulin autoimmune syndrome was suspected in our patient. The significantly elevated insulin autoantibodies level in insulin-naïve patients confirmed the diagnosis of insulin autoimmune syndrome. While the result of insulin autoantibodies was pending, we did not further investigate the unnecessary invasive procedures or surgical intervention in our patient. The age onset of 74 years old was around the peak age of onset in Japanese case series [11]. We assumed that the first episode of IAS with spontaneous remission occurred two years ago, and this episode was her 2nd attack. Uchigata et al. [11] reported that $82 \%$ of the patients in Japan had a spontaneous remission of IAS within 3-6 months, with the peak duration more than 1 and less than 3 months [11]. Our patient also experienced a three-month duration in the first episode and two-month period in the last episode. Thyroid autoantibodies and antinuclear antibody (ANA) were detected in the patient. Elevated ANA titer and thyroid autoantibodies, in the period of hypoglycemic attack, were decreased after the remission of disease along with the declination of fasting insulin and improvement of low plasma glucose. These findings support the association of IAS and autoimmunity. The upward changing trends of autoantibodies in the follow-up period may be the early indicator of relapsing disease.

The 75-gram OGTT in our patient showed a diabetic pattern at two hours with plasma glucose of $221 \mathrm{mg} / \mathrm{dl}$, corresponding to the diabetic pattern of $59 \%$ in autoimmune insulin syndrome patients reported by Uchigata et al. [2]. The ineffective insulin that bound with their autoantibodies as previously described can explain the mechanism of diabetic or impaired glucose tolerance pattern. Hypoglycemia developed at five hours after administration of 75 grams of glucose, one hour later compared with the result of Lupsa et al. [10]. In the mixed meal test, hypoglycemia developed at 
TABLE 1: Laboratory investigation during initial and subsequent follow-up period.

\begin{tabular}{|c|c|c|c|c|c|}
\hline \multirow{2}{*}{ Lab } & \multicolumn{5}{|c|}{ Time after the 2 nd episode } \\
\hline & 1st day & 4th month & 6th month & 12th month & 15th month \\
\hline FPG (mg/dL) & $44^{*}$ & 96 & 87 & 93 & 92 \\
\hline HbAlc (\%) & 5.7 & 5.7 & 5.8 & 5.7 & 5.8 \\
\hline Fasting insulin level $(\mu \mathrm{U} / \mathrm{mL})$ & $2628^{*}$ & 50.77 & 26.11 & 18.17 & 12.62 \\
\hline C-peptide level (ng/mL) & $8.3^{*}$ & - & 1.95 & 2.23 & 2.16 \\
\hline Insulin autoantibody level (nmol/L) & $10.7^{*}$ & - & - & - & - \\
\hline Anti-thyroperoxidase $\mathrm{Ab}(\mathrm{U} / \mathrm{mL})$ & 88.84 & - & 62.10 & 43.35 & 35.11 \\
\hline Anti-thyroglobulin $\mathrm{Ab}(\mathrm{U} / \mathrm{mL})$ & 169.26 & - & 114.11 & 68.11 & 72.40 \\
\hline Antinuclear $\mathrm{Ab}$ titer & $1: 320$ & - & $1: 320$ & $1: 100$ & - \\
\hline
\end{tabular}

${ }^{*}$ Results obtained during the hypoglycemic episode.

four hours, similar to the result from one of the patients from the study of Lupsa et al. [10]. In our patients, hypoglycemia was more severe, indicated by lower plasma glucose, together with the higher level of insulin after 75-gram OGTT than after mixed meal test; this could imply that the intake of simple carbohydrate can aggravate severe hypoglycemia.

A previous study by Uchigata and Hirata [7] in 330 Japanese IAS patients demonstrated that $78 \%$ of the patients had spontaneous remission or resolution after avoiding culprit drug exposure, 9\% required steroid treatment, $7.3 \%$ were treated with alpha-glucosidase inhibitor, $2.4 \%$ had severe hypoglycemia and required plasmapheresis, $1.8 \%$ underwent pancreatic surgery, and $0.6 \%$ were treated with other immunosuppressive drugs such as azathioprine and 6mercaptopurine. Our patient was successfully treated with dietary management mainly by avoidance of simple carbohydrate. Hypoglycemia spontaneously remitted within two months.

\section{Conclusion}

We reported a case of recurrence postprandial hypoglycemia with an extremely high insulin level leading to the diagnosis of insulin autoimmune syndrome, which was confirmed by the high level of serum insulin autoantibody. With this clinical syndrome, we can diagnose the cause of hypoglycemia in this patient and prevent her from undergoing unnecessary investigation and surgery.

\section{Conflicts of Interest}

The authors declare that there are no conflicts of interest regarding the publication of this paper.

\section{References}

[1] Y. Hirata, H. Ishizu, N. Ouchi, S. Motomura, M. Abe, and Y. Hara, "Insulin autoimmunity in a case of spontaneous hypoglycemia," Journal of the Japan Diabetes Society, vol. 13, no. 13, pp. 312-320, 1970.

[2] Y. Uchigata, Y. Hirata, and Y. Iwamoto, "Insulin autoimmune syndrome (Hirata disease): Epidemiology in Asia, including Japan," Diabetology International, vol. 1, no. 1, pp. 21-25, 2010.
[3] W.-Y. Ma, J. G. S. Won, K.-T. Tang, and H.-D. Lin, "Severe hypoglycemic coma due to insulin autoimmune syndrome," Journal of the Chinese Medical Association, vol. 68, no. 2, pp. 8286, 2005.

[4] N. Raizada, S. H. Rahaman, D. Kandasamy, and V. P. Jyotsna, "Rare association of insulin autoimmune syndrome with ankylosing spondylitis," Endocrinology, Diabetes \& Metabolism Case Reports, vol. 2015, Article ID 150090, 2015.

[5] I. W. Song, E. Han, N. H. Cho, and H. C. Cho, "Insulin Autoimmune Syndrome in a Patient with Hashimoto's Thyroiditis," Journal of Korean Thyroid Association, vol. 7, no. 2, p. 180, 2014.

[6] J. S. Han, H. J. Moon, J. S. Kim, H. I. Kim, C. H. Kim, and M. J. Kim, "Anti-tuberculosis Treatment-Induced Insulin Autoimmune Syndrome," The Ewha Medical Journal, vol. 39, no. 4, pp. 122-124, 2016.

[7] Y. Uchigata and Y. Hirata, "Insulin Autoimmune Syndrome (Hirata Disease)," in Immunoendocrinology: Scientific and Clinical Aspects, G. S. Eisenbarth, Ed., pp. 343-367, Humana Press, Totowa, NJ, USA, 2011.

[8] A. A. A. Ismail, "The insulin autoimmune syndrome (IAS) as a cause of hypoglycaemia: An update on the pathophysiology, biochemical investigations and diagnosis," Clinical Chemistry and Laboratory Medicine, vol. 54, no. 11, pp. 1715-1724, 2016.

[9] P. Sahni, N. Trivedi, and A. Omer, "Insulin Autoimmune Syndrome: a rare cause of postprandial hypoglycemia," Endocrinology, Diabetes \& Metabolism Case Reports, Article ID 160064, 2016.

[10] B. C. Lupsa, A. Y. Chong, E. K. Cochran, M. A. Soos, R. K. Semple, and P. Gorden, "Autoimmune forms of hypoglycemia," Medicine, vol. 88, no. 3, pp. 141-153, 2009.

[11] Y. Uchigata, Y. Eguchi, S. Takayama-Hasumi, and Y. Omori, "Insulin autoimmune syndrome (Hirata disease): clinical features and epidemiology in Japan," Diabetes Research and Clinical Practice, vol. 22, no. 2-3, pp. 89-94, 1994. 


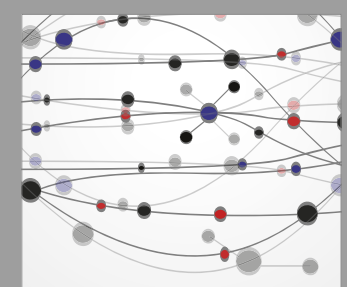

The Scientific World Journal
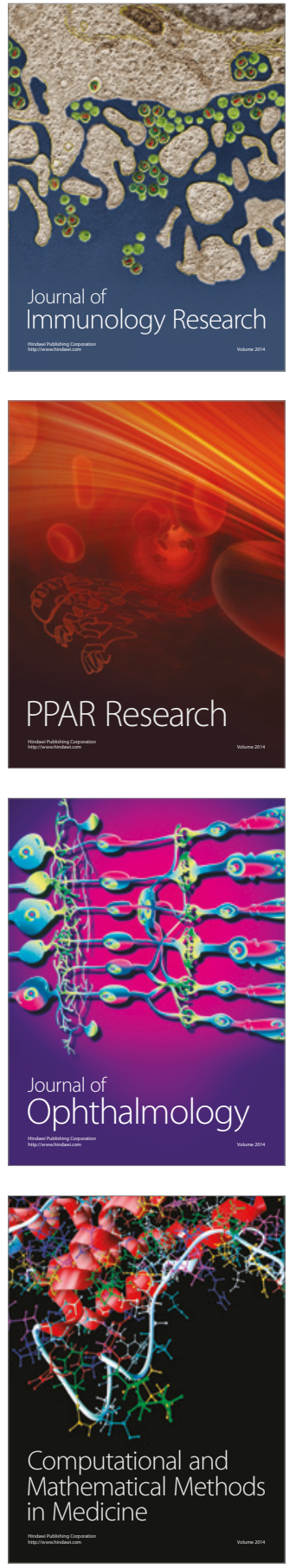

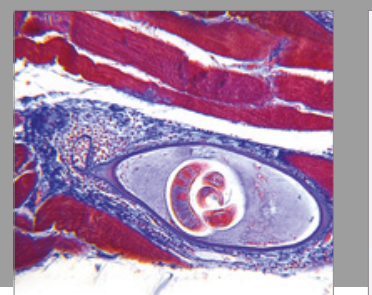

Gastroenterology Research and Practice
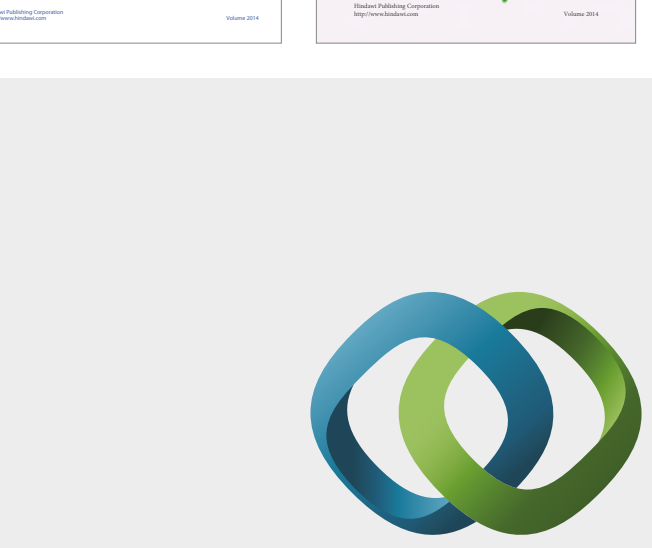

\section{Hindawi}

Submit your manuscripts at

https://www.hindawi.com
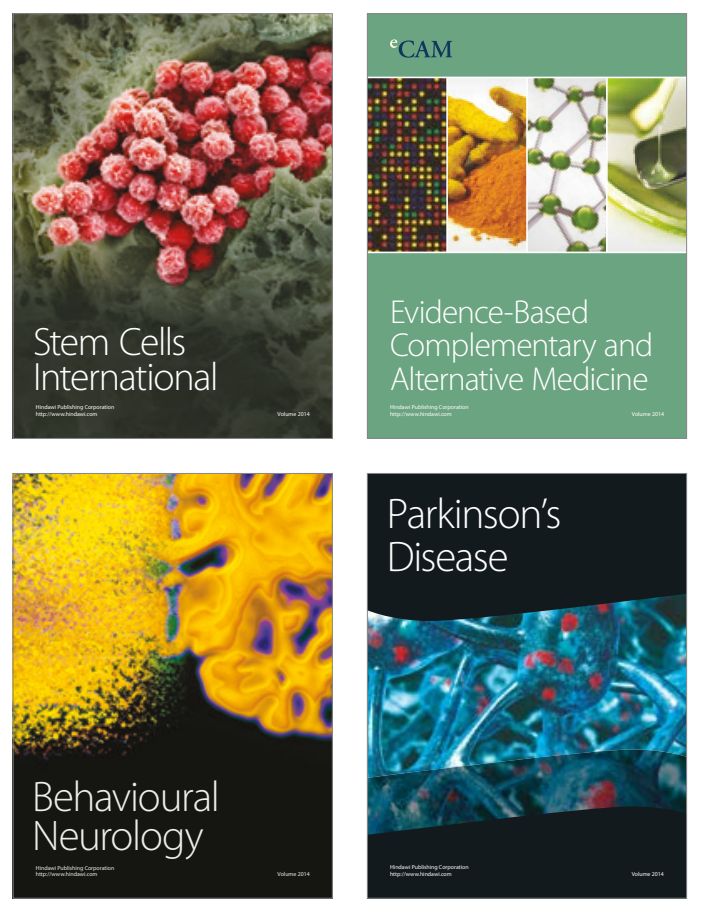
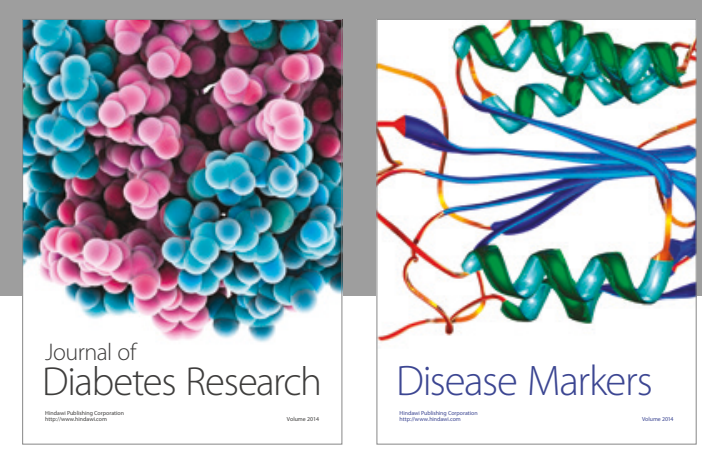

Disease Markers
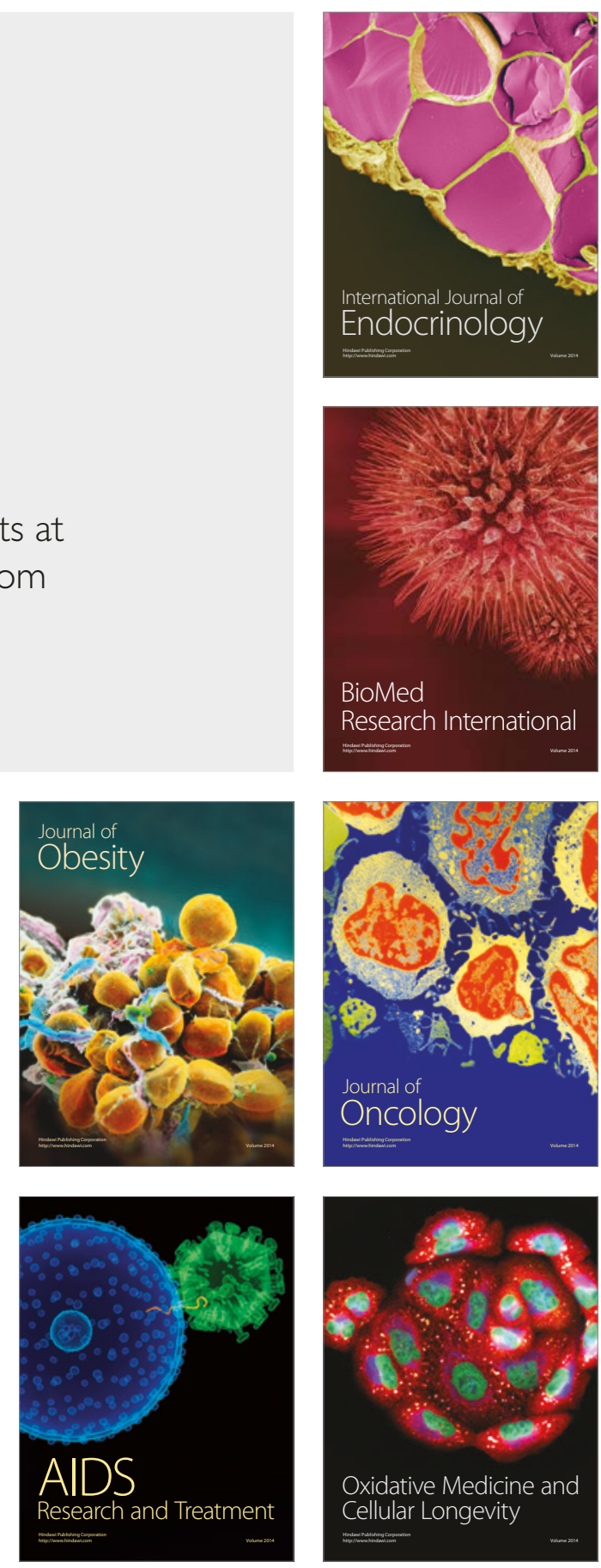